\title{
Oxygen free radicals in acute pancreatitis of the rat
}

\author{
M H Schoenberg, M Büchler, M Gaspar, A Stinner, M Younes, I Melzner, B Bültmann, \\ H G Beger
}

\begin{abstract}
This study aimed to assess the role of oxygen free radicals in acute pancreatitis. Acute pancreatitis was induced in rats by infusion of the CCK-analogue cerulein ( $5 \mu \mathrm{g} / \mathrm{kg}$ per hour) for 30 minutes, 3.5 hours, and 12 hours. After the infusion, serum enzymes and conjugated tissue dienes and malondialdehyde were measured and tissue samples were subjected to electron and light microscopy. Electron microscopy after $\mathbf{3 0}$ minutes showed moderate intracellular alterations. After 3.5 hours of cerulein infusion interstitial oedema and intravascular margination of granulocytes in the pancreatic gland were seen. After 12 hours histological evaluation showed pronounced zymogen degranulation, extensive tissue necrosis, and migration of granulocytes into the tissue. Amylase and lipase activities increased 15 and 35-fold respectively during this time. After 30 minutes of cerulein infusion conjugated dienes and malondialdehyde increased, they reached their peak after 3.5 hours and decreased to normal values after 12 hours. Treatment with superoxide dismutase (100 000 U/kg/hour) and catalase (400 $000 \mathrm{U} / \mathrm{kg} /$ hour) either before or after the start of the cerulein infusion prevented lipid peroxidation and reduced zymogen degranulation and tissue necrosis. Tissue oedema and inflammatory response, however, were not affected in any of the treated rats. Oxygen free radicals are instrumental in the development of acute pancreatitis. Even after its onset, scavenger treatment reduced the tissue damage normally observed.
\end{abstract}

Departments of General Surgery and Pathology, University of Ulm, West Germany

M H Schoenberg

M Büchler

$M$ Gaspar

A Stinner

I Melzner

B Bültmann

H G Beger

Department of Toxicology, University of Lübeck, West Germany $M$ Younes

Correspondence to:

Dr $\mathrm{H}$ G Beger, Department of General Surgery, University of

Ulm, West Germany

Accepted for publication

20 November 1989 pancreatitis. Sanfey et al caused acute pancreatitis in an ex vivo perfused canine pancreas by oleic acid infusion, partial duct obstruction, and a two hour period of ischaemia. These stimuli simulated an acute pancreatitis in man due to ischaemia/reperfusion injury, transient outflow obstruction, and alcohol-induced hyper- lipaemia. The authors showed that enhanced generation of oxygen radicals added considerably to the damages observed in all forms of pancreatitis. ${ }^{+5}$ Guice et al showed in an in vivo cerulein-induced pancreatitis model that pretreatment with superoxide dismutase and catalase reduced pancreatic damage normally observed. ${ }^{6}$ These results were recently confirmed by Wisner et al. In the same experimental model these authors were able to show that pretreatment with polyethylene glycol-linked superoxide dismutase minimised tissue oedema, histological damage, and the increase in $\alpha$ amylase in the serum. ${ }^{7}$

We used the same experimental model of cerulein-induced pancreatitis to monitor the generation of oxygen radicals and its relation to the development of acute pancreatitis. To assess the onset of free radical generation, we measured conjugated dienes and malondialdehyde, which are both indirect parameters for the formation of lipid hydroperoxides, at various times during the development of acute pancreatitis. We then compared them with the extent of tissue damage. In addition, we examined the effects of treatment with the oxygen radical scavengers superoxide dismutase and catalase, given before and after the onset of acute pancreatitis.

\section{Material and methods}

\section{EXPERIMENTAL PROCEDURE}

Fifty four male one strain WKY rats (weight ranging from $300-350 \mathrm{~g}$ ) were given inhalation anaesthesia with halothane, and a heparin rinsed polyethylene catheter was placed in the jugular vein. The animals were allowed to recover for 12 to 14 hours before being given an infusion of cerulein. The catheters were then flushed with $0.3 \mathrm{ml}$ normal saline solution in order to confirm patency before the start of the infusion. Thereafter, the cerulein (synthetic cerulein provided by Deutsche Farmitalia, Freiburg, West Germany) was dissolved in isotonic saline solution and infused continuously by means of a Havard pump via the implanted catheter. A standard dose of cerulein, $5 \mu \mathrm{g} / \mathrm{kg}$ per hour, was given at an infusion rate of $0.6 \mathrm{ml} /$ hour for periods ranging from 30 minutes to 12 hours. During infusion the rats had free access to pelleted food and water. After the infusion blood was sampled for plasma amylase and lipase measurements and pancreatic tissue samples were excised for light and electron microscopic 
examination and for determination of conjugated tissue dienes and malondialdehyde concentrations.

\section{CONTROL GROUPS}

Untreated rats were divided into four groups of 10 animals each. Control rats were prepared in the same way but received an isotonic saline solution for 12 hours instead of cerulein. The other three groups were infused continuously with cerulein (dosage see above) for $\mathbf{3 0}$ minutes, 3.5 hours, and 12 hours, respectively.

\section{TREATED GROUPS}

Fourteen rats were divided into two groups and received a continuous superoxide dismutase infusion (bovine superoxide dismutase by Grünenthal Co, Aachen, West Germany) at a dosage of $100000 \mathrm{U} / \mathrm{kg}$ per hour. In addition, the animals received during the first three hours a bolus injection of $400000 \mathrm{U}$ catalase (bovine catalase provided by Boehringer Co, Mannheim, West Germany), starting with the onset of the superoxide dismutase infusion. The treatment started one hour before the cerulein infusion (dosage: $5 \mu \mathrm{g} / \mathrm{kg}$ per hour) and paralleled this for 3.5 hours $(n=7)$ or 12 hours $(n=7)$.

In another set of experiments, seven rats were treated with superoxide dismutase and catalase using the same dosage, preparation, and method, but the treatment started one hour after the beginning of the cerulein infusion. After one hour the cerulein infusion was paralleled by the continuous superoxide dismutase treatment for 11 hours. In addition, catalase was given as an intravenous bolus for the first three hours after the beginning of the superoxide dismutase infusion. The cerulein and superoxide dismutase/catalase infusions were given through the same jugular catheter, since it had been shown previously, and reaffirmed before the experiments, that neither superoxide dismutase nor catalase affected the toxic properties of cerulein in vitro. ${ }^{6}$

\section{MEASUREMENTS}

Alpha amylase and lipase activities in the plasma were determined by a standard clinical method for automated analysis (amylase PNP, lipase automated analysis, Boehringer, Mannheim, Germany). The tissue concentrations of conjugated dienes and malondialdehyde were measured by the methods of Buege and Aust ${ }^{8}$ as well as according to Freeman and Crapo, ${ }^{9}$ and were corrected for the protein content of the tissue. The protein concentration of the pancreatic tissue was determined by the method of Lowry et al. ${ }^{10}$

\section{LIGHT MICROSCOPY}

Tissue samples removed from the caput, corpus, and cauda of the pancreas were fixed in a $5 \%$ formalin-picrin acid mixture for $\mathbf{2 4}$ hours, were paraffin-embedded, and then stained with haematoxylin and eosin. The light microscopical slides were examined and graded by the patholo- gist, who was unaware of the previous treatment (blind observer design).

GRADING AND STAGING SCALE

Oedema was graded $0-3$ : grade $0=$ no tissue oedema; grade $1=$ interlobular oedema; grade 2 =moderate interlobular and intra-acinar oedema; and grade $3=$ severe interlobular and intra-acinar oedema.

NEUTROPHILIC INFLAMMATORY RESPONSE

Neutrophilic inflammatory response was staged 1-3: stage $1=$ intravascular margination of granulocytes in capillaries and postcapillary venules; stage $2=$ granulocytes present in the perivascular tissue; and stage $3=$ diffuse infiltration of the entire pancreatic gland.

\section{CELL DAMAGE}

The extent of zymogen degranulation and cell necrosis was assessed planimetrically by counting the degranulated and necrotic cells in approximately 100 acinar lobuli per sample (at least four histological sections/sample). The frequency of degranulation and cell necrosis in the lobuli is given as a percentage.

\section{ELECTRON MICROSCOPY}

Immediately after the death of cerulein infused rats, $1 \mathrm{~mm}^{3}$ of their pancreatic tissue was removed and incubated in 3\% glutaraldehyde in phosphate buffer $(\mathrm{pH}=7 \cdot 3)$. After 10 hours the tissue was rinsed extensively in buffer and postfixed by incubation with $\mathrm{OsO}_{4}(1 \%$ in phosphate buffer). After fixation, the samples were washed in Veronal acetate buffer and dehydrated in a graded series of alcohols. Thereafter the samples were embedded in Epon 812. Sections were cut with a diamond knife on an LKB ultramicrotome, stained with $5 \%$ uranylacetate and lead citrate, and were examined with a Philips EM 10 A electron microscope.

Sixty acinar cells/tissue sample (one tissue sample/animal; five animals/cerulein-treated group) were evaluated for the content and distribution of zymogen granules, intracytoplasmatic vacuole formation, and damage to the organelles and membranes within the acinar cells. The results are given as the mean (SD) percentage of cells showing abnormal findings in each experimental group.

\section{STATISTICAL METHODS}

The data are expressed as mean (SD) values. The data were evaluated statistically by the Institute of Biomathematics and Statistics, University of Ulm. Differences in conjugated dienes, malondialdehyde, $\alpha$ amylase, and lipase in the plasma were tested pairwise for statistical significance according to the Mann-Whitney test and were reevaluated by the Student's $t$ test. In addition the histological data were evaluated for statistical significance using the Student's $t$ test for independent means. In all instances $p$ values of $<0.05$ were considered to be significant. 
Histological grading, assessment of cell necrosis, and zymogen degranulation at various stages of acute pancreatitis

\begin{tabular}{|c|c|c|c|c|c|}
\hline Groups & No & Oedema & Neutrophils & $\begin{array}{l}\text { Zymogen } \\
\text { degranulation }(\%) \\
(\text { mean }(S D))\end{array}$ & $\begin{array}{l}\text { Cell necrosis } \\
(\%)(\text { mean } \\
(S D))\end{array}$ \\
\hline Control & 10 & 0 & 0 & \multirow{4}{*}{$\begin{array}{l}0 \\
0 \\
20 \cdot 8(9 \cdot 7) \\
\text { (range: } 10-30) \\
84 \cdot 2(7 \cdot 4) \\
\text { (range: } 75-95)\end{array}$} & \multirow{4}{*}{$\begin{array}{l}0 \\
0 \\
12 \cdot 3(4 \cdot 5) \\
\text { (range: } 5-20) \\
60 \cdot 0(7 \cdot 1) \\
\text { (range: } 50-70\end{array}$} \\
\hline 30 Minutes after cerulein & 10 & 0 & 0 & & \\
\hline $3 \cdot 5$ Hours after cerulein & 10 & $1-2$ & 1 & & \\
\hline 12 Hours after cerulein & 10 & 3 & 3 & & \\
\hline $\begin{array}{l}\text { SOD/CAT: } \\
1 \text { hour before }\end{array}$ & 7 & 3 & 3 & \multirow{2}{*}{$\begin{array}{l}39 \cdot 3(10 \cdot 6)^{\star} \\
\text { (range: } 30-60) \\
50 \cdot 7(11 \cdot 7)^{\star} \\
(\text { range: } 35-70)\end{array}$} & \multirow{2}{*}{$\begin{array}{l}21 \cdot 0(6 \cdot 2)^{\star} \\
\text { (range: } 12-30 \\
21 \cdot 4(10 \cdot 7)^{\star} \\
\text { (range: } 10-40\end{array}$} \\
\hline 1 hour after & 7 & 3 & 3 & & \\
\hline
\end{tabular}

Effects of superoxide dismutase/catalase treatment. ${ }^{\star} \mathrm{p}<0.001$ compared with the corresponding value in untreated rats receiving 12 hours' cerulein infusion.

\section{Results}

\section{UNTREATED RATS}

Light microscopy of the pancreatic glands of the rats which had received a 30 minute infusion of cerulein showed that these seemed undamaged. The first lesions become apparent after 3.5 hours and affected the entire gland. They were characterised by a moderate interstitial oedema, intravascular margination of granulocytes, the beginning of zymogen degranulation, and patchy acinar cell necrosis (see Table).

These lesions became worse after 12 hours of continuous cerulein infusion. The tissue was severely oedematous and showed extensive zymogen degranulation and cell necrosis as well as a pronounced migration and accumulation of polymorphonuclear leucocytes into the tissue.

Even after 30 minutes of cerulein infusion electron microscopic examination showed the formation of small (in $54(11) \%$ ) and large (27 (11)\%) intracytoplasmic vacuoles and a reduction of zymogen granules in $46(27) \%$ of all acinar cells. Most impressive was the finding of swelling of the mitochondria in $60(15) \%$ of the cells, which in 14 (9)\% led to the disruption of the cristae and the matrix (see Figs 1 and 2).

After 3.5 hours the damage had progressed further, leading to large vacuoles in 57 (12)\% of the cells that indicated autophagic processes in the exocrine cell. Moreover, the tight junctions in $55(12) \%$ of the cells began to loosen as an early sign of cell membrane damage. After 12 hours' infusion the vacuoles were seen to occupy a large part of the acinar cells in 91 (9)\%, the oedema within the connective tissue had worsened, and polymorphonuclear leucocytes, as well as a few mononuclear cells, had accumulated in the interstitial space.

In contrast with the early changes seen by electron microscopy after 30 minutes, plasma values of both $\alpha$ amylase and lipase remained at control values. After 3.5 hours we measured a significant accretion of these enzymes, and after 12 hours their serum concentrations had increased more than 15 and 35 times respectively. Interestingly, the interindividual comparison showed no positive correlation between the amount of cell and tissue damage and the serum enzyme activities (see Figs 3 and 4).

As well as the early electron microscopical damage of the pancreatic gland after 30 minutes of cerulein infusion, the tissue concentrations of both conjugated dienes and malondialdehyde were raised. After 3.5 hours, the conjugated dienes increased progressively from $2 \cdot 3(0 \cdot 2)$ to $4.0(0.5) \mu \mathrm{mol} / \mathrm{mg}$ protein and malondialdehyde from $15 \cdot 7(2 \cdot 5)$ to $48(12) \mathrm{nmol} / \mathrm{mg}$ protein (see Figs 5 and 6 ).

After 12 hours, at which time the histological signs of acute pancreatitis were seen, both conjugated dienes and malondialdehyde returned to their control values.

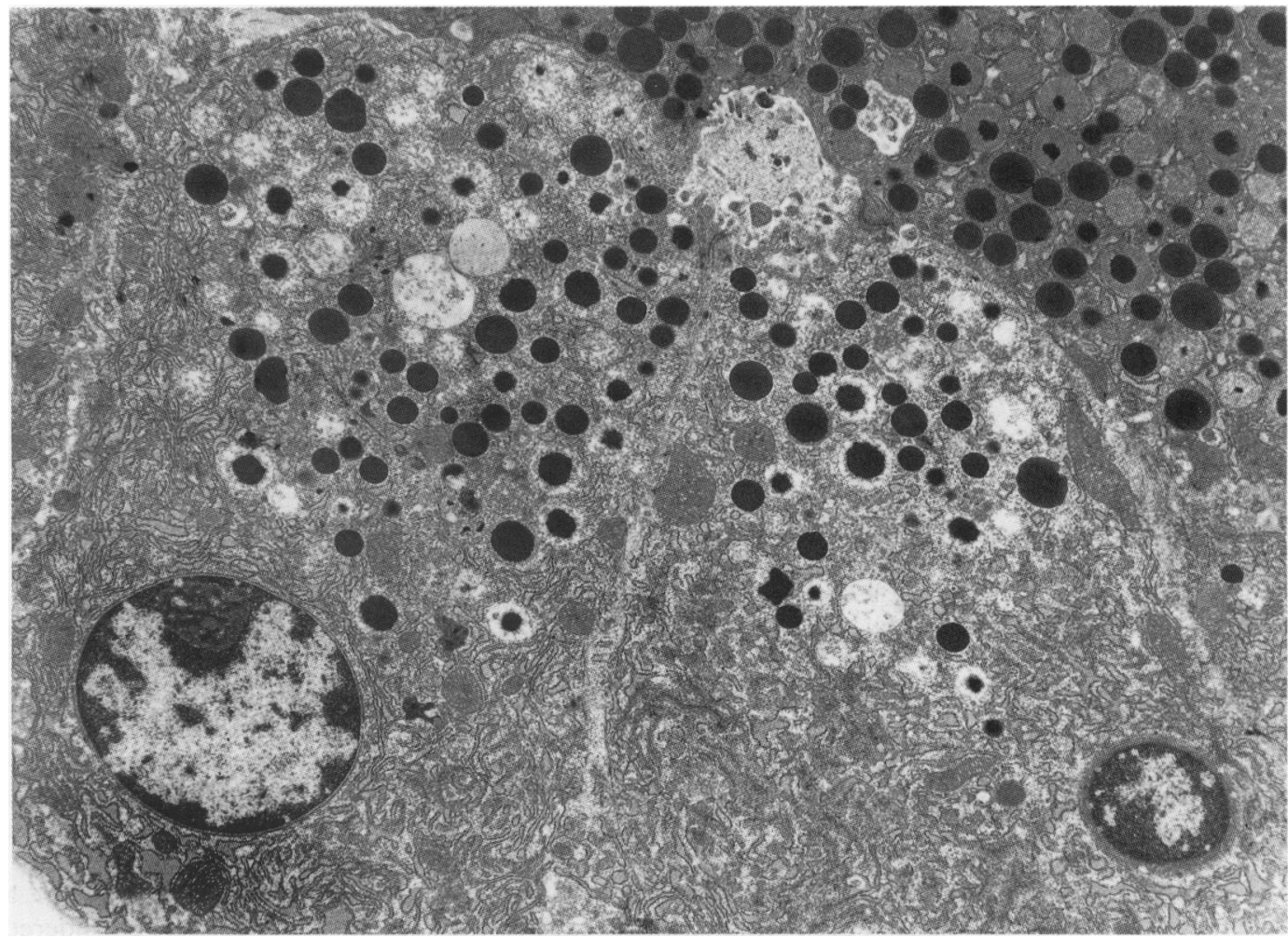


Figure 2: Enlargement of the electron microscopical picture (see Fig 1). Arrows show a swollen mitochondria with disrupted cristae (original magnification $\times$ $11000)$.

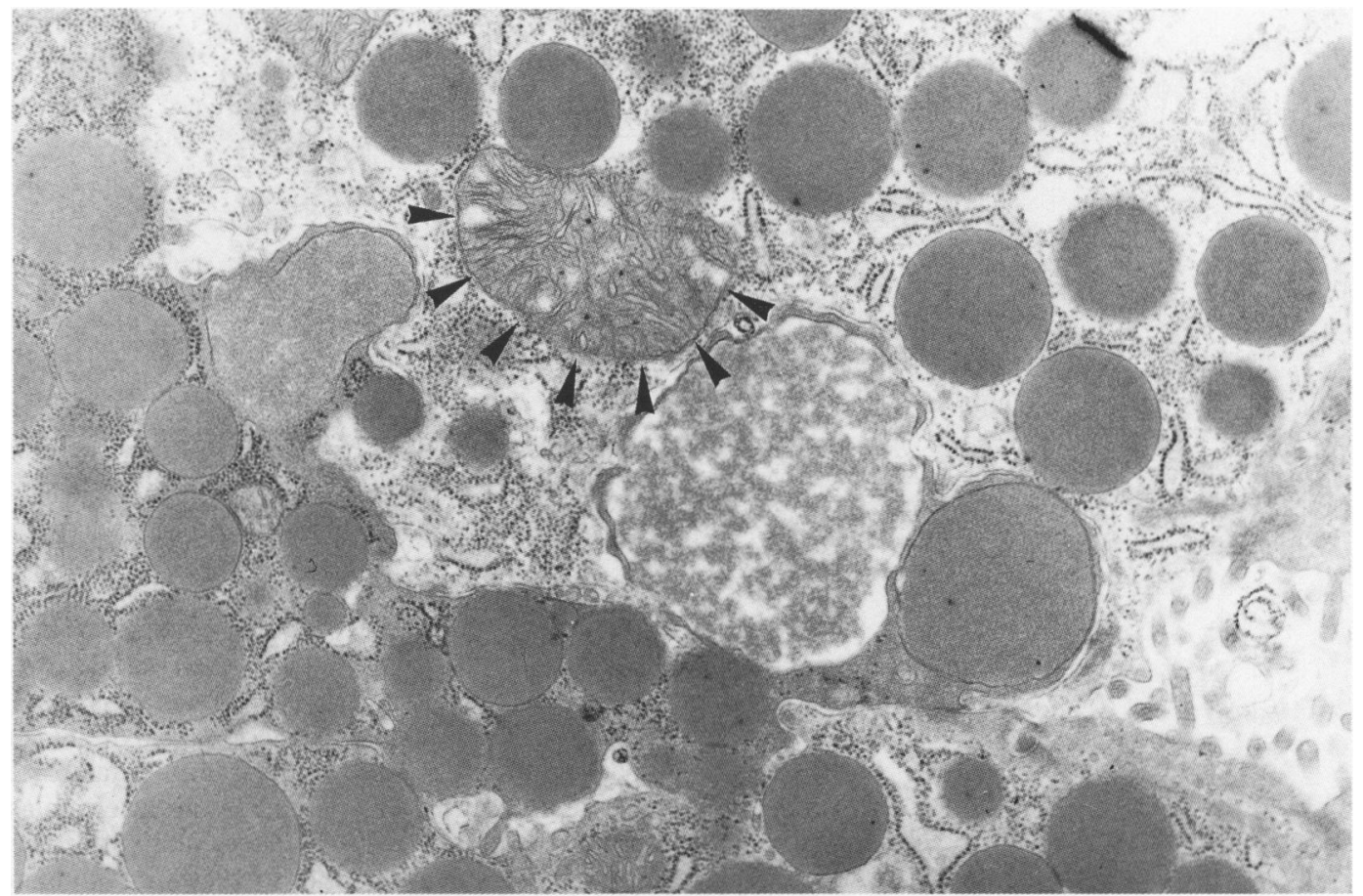

TREATED RATS

Superoxide dismutase and catalase treatment before infusion prevented the increase in conjugated dienes in the pancreatic tissue normally observed after 3.5 hours. At the same time the tissue malondialdehyde concentrations were only slightly raised. They did not, however, differ significantly from the control values. After 12 hours both conjugated dienes and malondialdehyde concentrations were the same as the normal range in the untreated rats (see Figs 5 and 6).

Histological evaluation of the pancreatic tissue after 3.5 hours of cerulein infusion in untreated and pretreated rats showed that there were no significant differences between the groups. After 12 hours of cerulein infusion, however, histological examination showed that superoxide dismutase and catalase treatment, given one hour before cerulein, reduced zymogen degranulation and acinar cell necrosis. Only $21(6 \cdot 2) \%$ of the acinar cells were severely damaged or necrotic compared with $60(7) \%$ in the untreated group $(\mathrm{p}<0.0001)$. At the same time, zymogen degranulation was $39 \cdot 2(10 \cdot 6) \%$, significantly lower than in the untreated rats $(84 \cdot 2(7 \cdot 3) \%)$

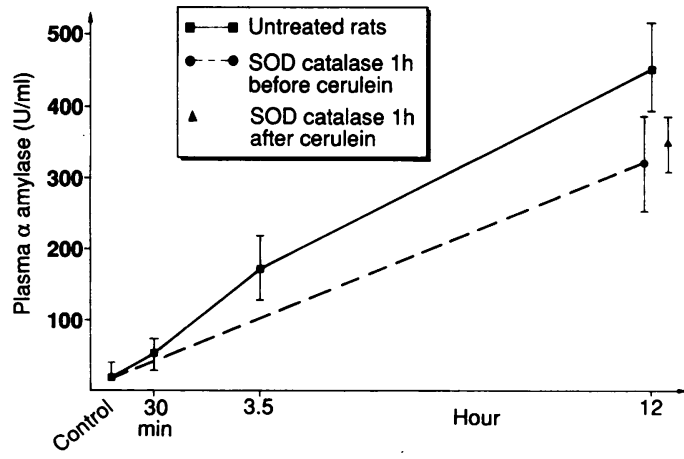

Figure 3: The changes of the pancreatic amylase in the plasma during the course of pancreatitis with and without scavenger treatment (mean $(S D)$ ). SOD= superoxide dismutase. $(\mathrm{p}<0 \cdot 0001)$. Pretreatment with superoxide dismutase and catalase, however, had no influence on the development of tissue oedema or the stage of inflammatory response (see Table). Moreover, in spite of the differences in zymogen degranulation, the enzyme activities did not differ significantly from the values after 3.5 and 12 hours in the untreated group (see Figs 3 and 4 ).

Histological findings in animals treated with superoxide dismutase one hour after beginning cerulein infusion showed almost identical oedema formation and the same stage of inflammatory response as those in untreated rats. The extent of cellular necrosis was $21.4(10 \cdot 6) \%$, significantly. less $(p<0.0001)$ than in untreated rats (see Table). Zymogen degranulation, although less than in untreated rats, was still more pronounced than in the pretreated group. At the same time, amylase and lipase activities were lower in the treated animals but because of the considerable variation the difference did not reach statistical significance (see Figs 3 and 4). As in the other experimental groups, the lipid peroxidation in animals treated one hour after cerulein infusion was the same as control values (see Figs 5 and 6)

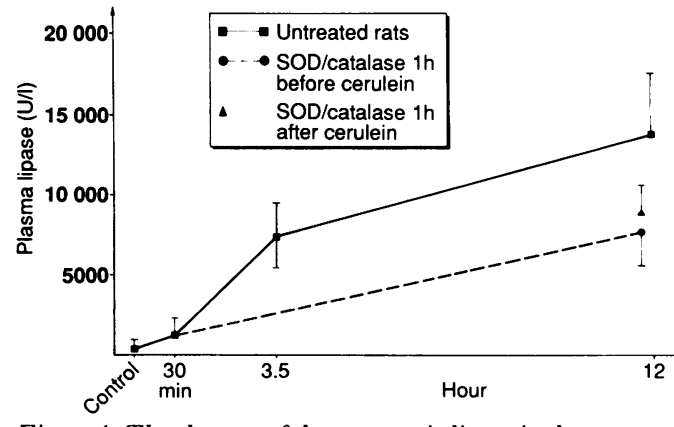

Figure 4: The changes of the pancreatic lipase in the development of acute pancreatitis and the effects of treatment with superoxide dismutase (SOD) and catalase (mean $(S D)$ 


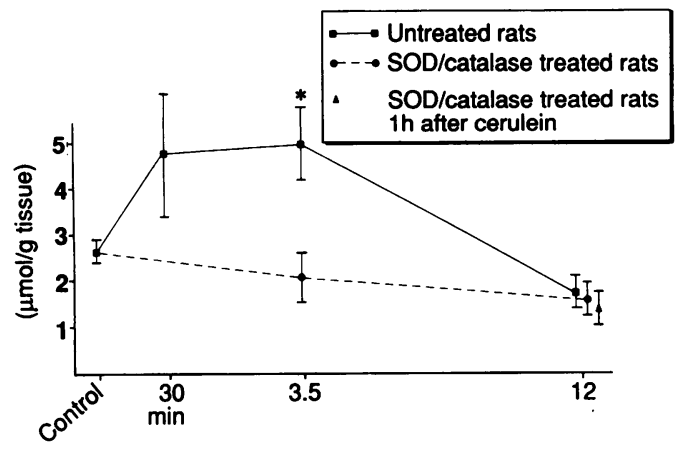

Figure 5: The changes in the tissue concentrations of conjugated dienes in pancreatic tissue during the development of the disease in untreated and superoxide dismutase (SOD) and catalase treated rats. ${ }^{\star S}$ ignificance $p<0.02$ level (mean (SD)).

\section{Discussion}

Oxygen radicals react preferentially with phospholipids of cell membranes. This direct reaction induces lipid peroxidative chain reactions within the membrane, disintegration of the cell membrane, and, finally, irreversible cell damage. ${ }^{.1}$ Indirectly, oxygen radicals generate a chemotactic factor which leads to an accumulation and margination of polymorphonuclear leucocytes in the damaged tissue. ${ }^{12}$

Because of their high reactivity, oxygen radicals are difficult to measure directly. Their involvement in various pathological mechanisms has therefore to be proved by circumstantial evidence. One possibility is to measure the amount of lipid peroxidation in the tissue and compare it with the development of tissue injury. Conjugated dienes or malondialdehyde, or both are by- or fragmentation products of lipid peroxidation $^{1314}$ and we measured these to assess the onset and further development of oxygen radical generation in our model of acute pancreatitis.

After 30 minutes of cerulein infusion, the tissue concentrations of conjugated diene and malondialdehyde had already increased slightly. Electron microscopy showed vacuole formation, the beginning of zymogen degranulation, and mitochondrial changes.

Conjugated dienes and malondialdehyde reached their highest tissue concentrations $3 \cdot 5$ hours after the start of cerulein infusion, and at the same time incomplete disassembly of tight junctions and moderate inflammatory reaction of the pancreatic gland was observed. After 12 hours of cerulein infusion, there was severe tissue oedema, cell necrosis, and a mainly neutrophilic infiltration of the pancreatic gland. At the same time the serum enzyme activities increased significantly. The tissue values of conjugated dienes and malondialdehyde, however, returned to normal. This is probably due to the extensive cell necrosis or further fragmentation of these labile products, or both.

The increase in these parameters at an early stage of acute pancreatitis suggests that free radicals induce enhanced formation of lipid peroxides in the tissue, before severe tissue damage can be seen on electron- and light microscopy. The individual increases in conjugated dienes and malondialdehyde as well as in $\alpha$ amylase and lipase in the plasma, however, did not correlate with the development of histo-

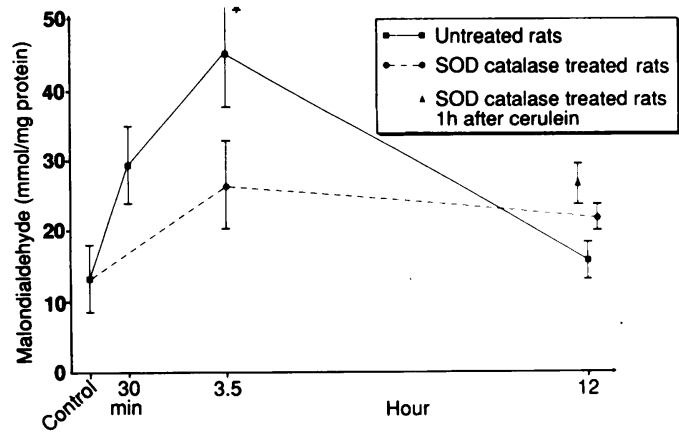

Figure 6: The development of malondialdehyde in the pancreatic tissue at various times after cerulein infusion. $\star$ Significance $p<0.05($ mean $(S D))$. SOD $=$ superoxide dismutase.

logical damage and the degree of inflammation.

Another indirect way of evaluating the role of oxygen radicals is to scavenge them by the highly specific antioxidant enzymes superoxide dismutase and catalase. In our model the superoxide dismutase/catalase treatment given before and one hour after cerulein infusion prevented an increase in conjugated dienes and malondialdehyde and reduced significantly the extent of zymogen degranulation and acinar cell necrosis. Tissue oedema and neutrophilic inflammatory response, however, remained as severe as in the untreated animals. These results suggest that once free radicals and their derivatives are generated at an early stage of disease, followed by direct or indirect membrane damage to the acinar cells, the later development of tissue oedema and inflammation seems to be independent of the enhanced oxygen radical generation. This may be explained by the further release of chemotactic stimuli (leucotrienes, complement activation) generated from the remaining necrotic tissue.

These results partly confirm those in the study by Sanfey $e t a l$, in which an ex vivo perfused canine pancreas preparation was used and an acute pancreatitis was induced by ischaemia, free fatty acid infusion, or partial pancreatic duct occlusion. Pretreatment with superoxide dismutase and catalase significantly reduced the pancreatic tissue oedema and hyperamylasaemia normally observed. ${ }^{+}$Wisner et al confirmed these results. In an acute pancreatitis model induced by a three hour cerulein infusion, treatment with polyethylene glycol-linked superoxide dismutase (PEG-SOD) reduced tissue oedema, serum amylase activity, and vacuolisation of the acinar cells. As in our study, treatment with PEG-SOD did not reduce the degree of inflammation. ${ }^{7}$ In contrast, Rutledge et al showed that in dietinduced haemorrhagic pancreatitis in mice, oxygen radicals were apparently of minor importance. Treatment with various scavengers reduced the peripancreatic oedema. All the other features that characterise this model of pancreatitis were unchanged. The development of the inflammatory response with and without scavenger treatment was not assessed in this study..$^{\text {is }}$

In all these studies, however, antioxidant treatment was given before the induction of acute pancreatitis. Guice $e t a l^{6}$ used superoxide dismutase and catalase treatment before and 
after a 12 hour cerulein infusion and compared the histological outcome and the recovery of the pancreatic gland. In their study a single postinjury injection of superoxide dismutase and catalase was as effective as a continuous infusion of these scavengers given at the same time as cerulein. In their model, however, the pancreas was examined 12 hours after the end of cerulein infusion, that is at a time when the pancreas is beginning to recover from the cerulein infusion. ${ }^{16}$

Nevertheless the study of Guice $e t$ al and our own results show that even after the initial onset of free radical generation and subsequent damage, treatment with free radical scavengers continues to be beneficial. This reflects the clinical situation more closely where the patient is admitted to the hospital after suffering from the first symptoms of acute pancreatitis.

Moreover, in patients suffering from pancreatitis, oxygen radicals seem to be important in the development of the disease. Braganza et al and Schoenberg et al found increased amounts of lipid peroxidation products, possibly derived from free radical oxidation, in the bile and tissue of patients suffering from acute or recurrent pancreatitis, or both. ${ }^{178}$ In addition, Braganza et al administered acetylcystein, a well known radical scavenger, to a patient suffering from multiple organ failure due to severe pancreatitis. Within 72 hours of the treatment the patient's lung and renal function improved considerably. ${ }^{19}$ Thus, it seems reasonable to assume that oxygen free radicals are generated in acute pancreatitis in man and add to the damage observed..$^{20}$ Consequently, treatment with free radical scavengers could possibly interrupt these damaging pathomechanisms and the development of complications, and improve the final outcome in the disease.

This study was supported by grants from the Deutsche Forschungsgemeinschaft, Bad Godesberg (Scho 309-2).
1 Adler G, Kern HF. Fine structure and biochemical studies in human acute pancreatitis. In: Gyr KE, Singer MV, Sarles H, eds. Pancreatitis. Amsterdam: Excerpta Medica, 1984: 3742.

2 Aho HJ, Nevalainen TJ, Havia VT, Heinonen RJ. Human acute pancreatitis. Acta Pathol Microbiol Immunol Scand $(A)$ 1982; 90: 367-73.

3 Bulkley GB. The role oxygen free radicals in human disease processes. Surgery 1983; 94: 407-11.

4 Sanfey H, Bulkley GB, Cameron JL. The role of oxygenderived free radicals in the pathogenesis of acute pancreatitis. Ann Surg 1984; 200: 405-13.

5 Sanfey H, Bulkley GB, Cameron JL. The pathogenesis of acute pancreatitis: the source and role of oxygen-derived free acute pancreatitis: the source and role of oxygen-derived free 1985; 201: 633-9.

6 Guice KS, Miller DE, Oldham KT, Townsend CM, Thompson JC. Superoxide dismutase and catalase: a possible role in established pancreatitis. Am $\mathcal{F}$ Surg 1986; 151: $163-9$.

7 Wisner J, Green D, Ferrell L, Renner I. Evidence for a role of oxygen derived free radicals in the pathogenesis of caerulein induced acute pancreatitis in rats. Gut 1988; 29: 1516-23.

8 Buege JA, Aust SD. Microsomal lipid peroxidation. Methods Enzymol 1978; 52: 302-10.

9 Freeman BA, Crapo JD. Free radicals and tissue injury. $L a b$ Invest 1982; 47: 412-26.

10 Lowry OH, Rosenbrough NI, Farr AL, Randell RI. Protein measurements with the folinphenol reagent. $7 \mathrm{Biol}$ Chem 1951; 193: 265-75.

11 Slater TF. Free radical mechanism in tissue injury. Biochem $\mathcal{F}$ 1984; 222: 1-15.

12 Petrone WF, English DK, Wong K, McCord JM. Free radicals and inflammation: superoxide-dependent activation of a neutrophil chemotactic factor in plasma. Proc Natl Acad Sci 1980; 77: 1159-63.

13 Floyd RA, Zaleska MM. Involvement of activated oxygen species in membrane peroxidation: possible mechanisms and biological consequences. In: Bors W, ed. Oxygen radicals in chemistry and biology. New York: de Gruyter, 1984: 285-96.

14 Younes M, Schoenberg MH, Fredholm BB, Haglund U. Oxidative tissue damage following regional intestinal Oxidative tissue damage following regional intestinal 15chemia $259-64$.

15 Rutledge PL, Saluja AL, Powers RE, Steer ML. Role of oxygen-derived free radicals in diet-induced hemorrhagic pancreatitis in mice. Gastroenterology 1987; 93: 41-7.

16 Adler G, Hupp T, Kern HF. Course and spontaneous regression of acute pancreatitis in the rat. Virchows $\operatorname{Arch}(A)$ 1979; 382: 31-47.

17 Braganza JM, Wickens DL, Cawood P, Dormandy TL. Lipid peroxidation products in bile of patients with pancreatic disease. Lancet 1983; ii: 375-8.

18 Schoenberg MH, Büchler M, Beger HG. Lipid peroxidation products in the pancreatic tissue of patients with acute pancreatitis. BrF Surg 1988; 75: 1254 .

19 Braganza JM, Holmes AM, Morton AR, Stalley L, Ku R, Kishen R. Acetylcystein to treat complications of pancreatitis. Lancet 1986; i: 914-5.

20 Braganza JM, Rinderknecht $H$. Free radicals and acute pancreatitis. Gastroenterology 1988; 94: 1111-2. 